\title{
EXPLORING PEER REVISION AS A STRATEGY IN THE ESL WRITING CLASSROOM
}

\author{
Anie Attan \\ Language Academy \\ Universiti Teknologi Malaysia \\ and \\ Harlina Khalidi \\ SMK Mohd Khalid Johor Bahru
}

\section{ABSTRACT}

One of the issues affecting the efficacy of peer revision in the writing classroom is that of the knowledge of peer reviewers. Do peer reviewers have sufficient knowledge of content and language to critique the works of their peer writers? Do they provide feedback on content as much as they do for language? Proponents of social constructivism posit that learners learn best when they are involved in exploring, discovering and transforming their ideas and those of their peers through interaction, negotiation and collaboration. In the writing classroom, student writers and reviewers are given the opportunity to build meaning based on their own experiences. This study examined the types of comments made by Malay ESL peer reviewers and their perceived usefulness towards improving peer writers' composition. Comments on peer writing were collected from ten upper secondary school peer reviewers for equal number of peer writers through reviewer feedback form, peer conferencing session, reviewer field notes and writers' multiple drafts. Findings of the study show that peer reviewers were able to provide revisions in both areas of content and language. Additionally, the strategies used to providing feedback on content included alteration and reordering, clarification and suggestion, as well as praise and criticism. Overall peer revision has a positive impact on writing and this has implications for teaching and learning, more so for teachers who are overburdened with marking.

Keywords: Peer revision, constructivism, English as a Second Language, common errors, strategies to correct errors

\section{INTRODUCTION}

Peer revision is a crucial aspect of process writing. Peer revision has gained widespread acceptance in modern advanced writing classrooms as learning and assessment tool and is increasingly being experimented for its use as an interactive peer learning and assessment tool in online writing classes and technology-enhanced environments (Keppell et al 2006; Knight \& Steinbach 2011). Peer revision is a process whereby learners evaluate one another's work for better quality writing. Learners generally view it as a non-threatening activity as both reviewers and writers benefit from the feedback that their peers provide (Wood \& Kurzel 2008). Wessa \& De Rycker (2010) echo the same mutual benefits gained from encouraging learners to review each other's work. The writer whose work is being reviewed benefits from the analysis and synthesis that the reviewer shares with him while the reviewer who provides the nurturing gains new experiences whilst sharpening his critical thinking ability and language skills during the revision process. The theoretical basis for the use of peer revision for the development of writing skills is rooted in Vygotskyan Social Constructivism which sees learning not as an individual activity but a collaborative effort mediated by social interaction (Lu \& Bol 2007). In the Vygotskyan social interaction framework, culture, peers and adults play important roles in influencing learners' development. This influence, expressed as the Zone of Proximal Development, refers to the difference in a learner's performance when he attempts a problem on his own compared 
with when an adult or older learner provides assistance (Vygotsky 1978). For example, a beginner learner may have difficulty with writing narrative essays but with the coaching of a competent writer on techniques to develop the appropriate mood in the writing and use of appropriate words and expressions to create the desired effect, the beginner learner will, with time, develop the skills of writing effective narratives. The more experienced peer is, in this instance, providing the beginner learner the scaffolding needed to support his evolving understanding of knowledge and development of complex skills. Scaffolding is thus a strategy for supporting the intellectual knowledge and skills of a learner and facilitating intentional learning (Donato 1994) Learners, in this instance, are allowed to experience learning with the help of their peers, given ample opportunities to discover, explore and transform their ideas and to respond to their peers' suggestions. Through collaboration, learners promote their own learning by giving explanations and expressing ideas from their own perspective. In speaking, Franklin (2010) noted that learners improve their conversational skills when given the opportunity to freely express their opinion.

Research on the value of peer revision shows positive results in many writing classrooms. First, peer revision helps writers to be aware of their audience as well as their purpose for writing through the multiple responses given by their reviewers. Peers provide immediate, socially appropriate audience and motivation for writers to revise their work. Peers, as audience, are more sympathetic to their writers compared to the judgmental teacher audience who assessed an essay from purely a teacher's point of view (Rollinson 2005). Second, peers also help writers to identify the strengths and weaknesses of their essays and to suggest ways to improve their writing (Blasingame \& Bushman 2005). With the feedback given, writers have multiple opportunities to re-write and improve and subsequently learn more about writing and revision (Chaudron 1984). The number of revisions increases as students find that feedback given by their peers is more understandable and effective, compared to teachers' comments which can be confusing as they might use professional jargon which may be difficult for them to understand (Cho et al 2008). For example, it was found that students gave more priority to peer revisions than teacher feedback as they saw more social support in peer reviewers' comments and suggestions (Elbow 1973). Third, peer revision can generate a rich source of information to address content and rhetorical issues, enhance intercultural information and give students a sense of group cohesion (Hansen \& Liu, 2005). The socially supportive peers can help in development of ideas and allowing peer writers to gain more confidence to express their ideas during brainstorming sessions (Mendonca \& Johnson 1994).

However, the literature also shows that there are problems with implementing peer revision. Peer revision is a complex activity and requires careful training and structuring (Villamil \& Deburro 1996). Besides it also depends on a cooperative environment among group members which can be difficult as students may come from different backgrounds and cultures (Allaei \& Connor 1990). Size of group is another consideration, in which the larger the size, the more unmanageable it becomes in giving every member an opportunity for intensive discussion (Hu 2005) as well as helping apprehensive and blocked writers to become fluent (Legge 1980). Level of trust in favour of the competent reviewers and inclination towards the capable and more experienced reviewers (Stritjbos, Narciss \& Dunnebier 2010) are other worthy considerations. Studies have shown that student writers do not think highly of their peer reviewers, perceiving them as not qualified enough to critique their work, based on the responses given which appeared vague and ineffective and rarely contributing to substantial help towards improving their writing (Neubert \& McNeds 1990). Tsui and $\mathrm{Ng}(2000)$ noted that without knowledge, peer reviewers may also be unable to provide concrete and useful feedback. Consequently, it would be difficult for students to respond to the feedback given and as had been shown, they may not even trust those comments (Carson \& Nelson 1996). In the context of a developing ESL writing classroom, fraught with problems of limited English class hours, large class size, overworked teachers who may not be able to give full attention to students' writing, lackadaisical attitude and motivation displayed by students towards feedback given by teachers to their writing and scarcity of research done on ESL peer 
revision have all sparked interest into the feasibility of peer revision as a strategy in the classroom to encourage and motivate learners to assist one another in their quest to become better writers and to create a more conducive learning environment. With the purpose of wanting a better understanding of how ESL peer reviewers help peer writers learn to write more effectively, this exploratory study was conducted to seek answers to the following research questions:

Research Question 1: What are types of revisions provided by the peer reviewers in peer revision?

Research Question 2: What is the impact of peer revision on peers' writing?

\section{METHOD}

The study was conducted on Form Five students of a secondary school located in the southern state of West Malaysia. Subjects were ten pairs of students, each pair comprising an advanced student (AS) and an intermediate student (IS). The sample was selected by stratified sampling from an initial seventy-eight of the population. The students were given an English Language selection test and based on the marks obtained by the students, the top ten and the bottom ten were selected. The top ten were assigned to the advanced students group (AS) while the bottom ten were assigned to the intermediate students group (IS). The reason for this categorization was to enable the AS to provide the cognitive, language and social support deemed needed by the IS throughout the revision activity. The sample was required to write two narrative essays in two cycles. For the two cycles, the students wrote on two different topics.

The instruments used in this research were two compulsory writing tasks, peer feedback form and a peer revision manual. For the two writing tasks, writers were required to construct a narrative essay in about 350 words based on an introductory sentence. The feedback form required the reviewers to write their feedback about their peers' writing. Feedback can be in the form of praises, comments, suggestions, evaluation, general opinion and explanation on the students' mistakes. The feedback form was to be completed at the end of each cycle. Prior to the peer revision activity, the sample was given a briefing and training on the whole peer revision exercise which included identifying areas that the peer writers could improve, identifying errors made and manner to indicate the changes to be made. Besides, they were also given training on manner and content to be included in the peer feedback form and reviewer field-note. The training to help the sample familiarize with the whole peer revision process was undertaken over a week and a peer revision manual as reference material was given to each student. The manual contained three sections. The first showed step-by-step procedure that both student writers and reviewers needed to do during the revision process. This included manner of annotating errors and manner of writing their comments and feedbacks. The second showed more specific guidelines to probe on aspects of narrative writing such as structure of essay, content, organization, vocabulary and grammar. This section was particularly set to guide the reviewers to identify specific problems in the drafts based on their occurrence. The final showed an error checklist for student reviewers to state the types of grammatical errors made by the writers. The training also included a mock peer conferencing session in which the peer reviewer and peer writer engaged in paired interaction to inform and explain the corrections to be made, seek clarification to ambiguous expressions and to suggest alternative expressions and idea development so as to improve the writing.

Data on the process of peer revision was collected systematically from three sources namely, students' multiple drafts from the two writing cycles, transcripts of the audio-taped peer discussions and the peer feedback forms. The writing sessions took place in the classroom and were being monitored by the teacher. Altogether a total of 200 minutes was recorded for a whole week, in two to three class sessions, each lasting 40 minutes. Within the 200 minutes, activities of brainstorming, outlining, 
drafting, revising and editing in pairs were carried out in class; however, due to limited time given to English Language learning, further work on essay completion took place outside the classroom. This was to enable the students to continue with the whole peer revision process of writing engagement, peer conferencing and making changes to their writing. Peer reviewers will also be entering their feedback forms and making field-notes after class hours as formal learning time allotted was limited to 200 minutes per week.

For each cycle, students produced at least three drafts. Errors annotated by the AS on each draft were recorded and compiled. These errors were further coded and classified according to categories. Reviewers' written comments on feedback forms were also classified according to the respective categories. Changes in each draft made by writers were also noted, coded and classified. The audiotaped recordings were transcribed and the transcripts of the interactions between the peer writers and peer reviewers analysed for a detailed understanding of the peer revision process and determining whether writers agreed to and adopted the feedback given by their reviewers. The impact of peer revision was to be determined through structure use, organization, idea development and vocabulary use.

\section{RESULTS AND DISCUSSION}

The results of the study are presented in answer to the research questions as follows:

Research Question 1: What are types of revisions provided by the peer reviewers in peer revision?

Several types of revisions were identified in which data were obtained from the transcripts of the peer conferencing session and writers' multiple drafts. Analysis of the interactional discourse between the reviewers and writers and revisions provided by peer reviewers on writers' multiple drafts suggested several patterns of contributions. They are as follows:

\section{Clarification and Suggestions}

Clarification comprises any kind of requests for additional information, either word or sentence meaning addition. Besides, it can also be a request for explanation of the translation of words or ideas made by the writer. The common structures of clarification used were "What do you mean by ....?", "Why did you use...?" or "Is this .....?". Following the request for clarification, another type of revision that goes hand in hand with clarification was suggestion. For this, the reviewers offered a better and workable improvement to the writers' next draft.

A total of 28 requests for clarification were found in the transcripts. Clarification was needed as the translation made was not clear to the reviewer. For example, when reviewing a writer's draft, the reviewer had underlined the whole sentence with a short remark written on the side of the paper asking 'What do you mean by this?' Such a remark indicated that he was unclear with the writer's intended meaning. To clarify this, both reviewer and writer got together to elucidate what was the exact message that the writer had intended to express. Following is an exchange between the reviewer and writer:

Reviewer: For this part, "...my heart pumped and I felt dizzy..., what do you actually mean by this?

Ko rasa apa sebenarnya masa tu? [ What did you actually feel at that moment?]

Writer: Aku nak cakap aku takut. Bulu roma meremang. Apa ... in English? [I wanted to say I was scared at that time. What is 'bulu roma meremang' in English?] 
When the writer used the expression that her heart 'pumped' and she felt 'dizzy' after seeing a ghost, the reviewer was unclear as both words 'pumped' and 'dizzy' seemed inaccurate to portray her fear. In order to clarify the confusion, the reviewer asked the writer what she had actually wanted to express and further offered her a better way to express her fear in her writing.

He then started to provide new input as was requested by the writer:

Reviewer: Oh, 'bulu roma meremang' in English, you can say 'having goosebumps'.

And he further continued by offering a suggestion to sum up the writer's whole situation, feeling and emotion,

Reviewer: So, for this part, you can write, "I was shivering in fear that I had goosebumps and I felt dizzy at the same time."

In another group, clarification and suggestions were done for vocabulary change. Some writers may have used inappropriate words or phrases to express their ideas. Most reviewers were able to identify, explain and offer practical suggestions for the writers.

Reviewer: You said here '.. I tried to cool down my brother'. Well, 'cool down' is much more for stuff like air-cond, car engine and all that.

The reviewer then offered a better word that met the writer's intended meaning.

Reviewer: You can replace 'cool down' with the word.....umm..'comfort'. So here you can say, I tried to comfort my brother'.

Clarification and suggestion were also made for structure and grammar. For example, the reviewer pointed out a grammar mistake by making a clarification request to check whether the writer was aware with the error, and it seemed that with the question, it helped the writer to spot her errors without being too dependent on the reviewer to provide her with the information.

Reviewer: Deanna, try to look at this 'I was very tired. After that, I heard a scared sound..'. Do you realize that there's a mistake there. Something doesn't sound right?

Writer: '... the scared sound?'

Reviewer: Yeah, you're right. It's supposed to be ' ... a scary sound'

As the writer was concerned about her grammar mistakes, she further asked the reviewer about the grammar rule applicable in the sentence,

Writer: Why was it wrong?

Reviewer: Because 'scary' is an adjective to describe a noun, in this case ...sound

Writer: oohhh, ..then 'scared'?

Reviewer: 'scared' is a verb. 'kata perbuatan'. Like..for example..if you say 'The noise scared me'. The word 'scared' is a verb.

From this extract, it is clear that the writer was able to obtain useful information from the session as the reviewer was able to cooperate as he understood the writer's problem. Having the proficiency and a good understanding on the nature of the error enabled him to explain further on the grammar 
rule. As we can see, from the specific part of the conferencing session, the writer was able to incorporate not only the correct form of the sentence but also obtained new information on the difference between the word 'scared' and 'scary' when writing her next draft.

As part of distinguishing the quality of peer revision and the conferencing session, other than the reviewer's proficiency and knowledge, the writer's initiative and effort to write better is crucial as more input and improvement can be expected from the peer conferencing session if there is full participation and positive attitude from the writers. Reviewers would be able to offer more help if the writers were able to understand their own problems and pose more follow-up questions.

\section{Alteration and Reordering}

Alterations are errors that are explicitly corrected by the reviewers. Alteration is said to be made when the reviewers identify an error and provide the correct form for the writers. Errors were indicated through underlining or circling the errors and the correct form written on top of the error. Most annotations (underlining or circling) were grammar related and since the writing task required the writers to write a story, it was projected that the writers committed errors related to tense. For example, Draft 1:

"Afifah, what did you do here?" my father asked a question.

The reviewer was able to identify and annotate the error and provide the correct form. The reviewer underlined the whole phrase 'did you do' and wrote the correct phrase on top of it, are you doing

"Afifah, what did you do here?" my father asked a question.

This is an example of how the writer made a grammatical error and was corrected directly by the reviewer. In the conferencing session, the writer had the opportunity to ask questions regarding her errors and at the same time received extra explanation from the reviewer. The following exchange illustrates this point:

Writer: Yang ni, bukan kena guna 'past tense' kan? [for this..I don't have to use the past tense right?] - when referring to the sentence.

Reviewer: Why? this is not a past tense. This is a conversation that took place when you were speaking.

Writer: Oh, so kalau kita tengah cakap sekarang, kita tak guna 'past tense? [oh, so if we are talking right now, we don't use the past tense?]

Reviewer: Yeah, it is like there was something happening when you were speaking, so the action, the verb, you must put '-ing'. Like this in your sentence, your father entered the room right?

Writer : Yes, okay. then?

Reviewer: Okay, so your father saw you then he asked the question right?

So, he saw you and he asked you the question "What are you doing here?" Use 'are' and '-ing'. Not the past tense.

During the conferencing session, it was noted that the reviewer had tried her best to explain the grammatical rule. Although explaining why the writer should use the present continuous tense instead of the past tense can be quite challenging, the reviewer tried hard to explain the rule of the grammar. $A$ lack of knowledge on grammar could be the sole reason why some reviewers were unable to provide a detailed and understandable explanation on certain grammatical rules. Students were still in need of input from teachers when it comes to explaining grammatical rules. However, the immediate help and assistance offered by peer reviewers would definitely play a big role in helping the writers to write better 
as they were already equipped with the correction of the errors plus explanation of the grammatical rules in which the teacher may not have the time to do.

In another situation, some reviewers were able to annotate the errors as they knew what was correct and what was incorrect. However, there was a risk for the writer to receive inaccurate explanation due to a lack of knowledge of grammatical rules. For example:

Reviewer: "Suddenly I felt someone sit beside me." This should be

Writer : Why?

"...someone sitting beside me"

Reviewer: 'sitting beside me'..hmmmmm...

Writer : '-ing'? Gerund?

Reviewer: maybe...

This is an example of the reviewer's inadequacy that can be damaging to the writer. The reviewer can be considered a proficient speaker and detecting the error was not a problem for him. However, he faced the problem of explaining the error. Some reviewers used statements like 'it sounds right', 'I think so' or I'm not so sure', 'maybe', in responding to writers' quest for explanation. This reflects the reviewers' limited capability which also led to only simple repairs made by writers or even repetition of the same mistakes as they did not have a complete understanding of the errors that they have made. In the above example, the writer had received inaccurate information on gerund and its use, i.e., verbs ending with -ing. The explanation to the correction should have been 'past continuous tense' instead of a 'gerund'.

Another type of revision which involved a more complex process compared to alteration was reordering. Reordering can be defined as rearranging sentences that lack coherence, connection and development. This type of revision required reviewers to correct and rewrite the whole structure of a sentence which appeared to be incorrect or confusing to readers. Following is an example of reordering from an analysis of a student's multiple drafts:

Draft 1:

I went there to meet the boy and asked but when I am in front of him, he said "Go, you are not supposed to be here"

Although on the surface it seemed there was not many errors committed by the writer except for the fact that there were omission of words in which the reviewers can make minor alterations, the reviewer who was very helpful made the effort to reorder the sentence by rewriting the whole sentence on top of the original sentence:

Draft 2:

I quickly approached the boy and asked him but the boy said, "Go away! you are not supposed to be here... I just wanted to be alone."

By still preserving the original meaning and idea of the writer, the reviewer provided a better version of the sentence which she thought would have sounded better to the essay. Besides that, reordering also involved substitution of vocabulary as the reviewer discovered there were alternative words which would have given better effect to the writing:

Draft 1:

I am in bed and in my bedroom and was about going to sleep......

After reordering, 
Draft 2:

I was in bed and was about to doze off......

Other than correcting the grammar of the sentence, the reviewer had tried to substitute the phrase 'going to sleep' with a better phrase 'doze off' which had given a better effect on the student's writing. If in alteration, both writer and reviewer were more form-focused and preoccupied with producing correct English, reordering provided the opportunity for the writer to increase her vocabulary.

\section{Praise and Criticism}

Another type of feedback was praise and criticism. Results indicated that 61 percent of all comments were related to praise and the other 39 percent to criticism. Following are examples of praise comments made by reviewers:

1. It's not that bad....it's good.

2. I really like your ..........

3. Good one!

4. Good job.

5. To me, this is good.

6. Interesting.

7. This type of sentence can really get you a high mark.

8. Impressive

9. Nice story.

10. Keep it up!

Praise feedbacks were in two forms, general or specific. General praises were those found on the peer response form that reviewers used to write their comments. Examples are 'good writing', 'good story'. Specific praises were those seen on students' multiple drafts. For example, positive reinforcement gained from positive comments for using new vocabulary, phrases, expressions and even sentences to add more effect to their writing. For example:

Reviewer : : Did you see this yellow highlighted part? I really like this.

Writer : : smiling).

Reviewer : This is good. When you describe the face? You wrote 'hideous face'. Actually you can just say 'the face'..

Writer : : Yes, but I want to say that the face is ugly

Reviewer : the word 'ugly' is common but the word 'hideous' is something different. Good job!

The underlined phrases are examples of praises given by a reviewer during peer conferencing session. This type of positive feedback reinforced the use of good word when writing the next draft and also the writer would know that the word 'hideous' was an adjective that she would be able to use when describing a face.

Another type of feedback applied by student reviewers was criticism, used to express their dissatisfaction on certain parts of the essay that they do not like. From the table, only few criticisms were received by writers and most of them did not contain any specific commentary for improvement. The following are examples of criticisms made by reviewers:

1. ...your words are not suitable.

2. Your grammar is quite bad. 
3. Too many errors.

4. Too many mistakes.

5. Your storyline is boring.

6. Sound less interesting.

7. Don't like the ending.

8. There are lots of mistakes.

Criticisms may be given directly or indirectly. In this study, some reviewers expressed their criticisms openly through their written comments in feedback forms and also during the peer conferencing session. Some others were more diplomatic, choosing not to give adverse comments which may strain their relationship. Female reviewers were more concerned with maintaining good friendly relationship with their writers while male reviewers were more frank in giving and accepting criticisms.

Research Question 2: What is the impact of peer revision on peer writing?

Successful revision can be seen in several ways. One of the indicators is when the feedback given was incorporated in the writing. The finding of this research showed that between Cycle 1 and 2, there was an increase in the number of student writers who incorporated more than 50 percent of peer feedback. Majority of the students incorporated feedback on structure and grammar annotated in the multiple drafts, followed by feedback on content annotated in the multiple drafts and peer conferencing and least on feedback from the peer response form.

\section{Incorporated peer feedback}

The incorporation of peer feedback by the writers in their multiple drafts is as follows:

Table 1: Distribution of Students Incorporating Peer Feedback ( $N=10)$

$$
\text { More than } 50 \text { percent Less than } 50 \text { percent }
$$

\begin{tabular}{lll}
\hline Cycle 1 & 4 & 6 \\
Cycle 2 & 7 & 3
\end{tabular}

The results in Table 1 show the difference in number of writers who incorporated peer feedback in their drafts. In Cycle 1, only four students incorporated more than 50 percent of peer feedback in their revisions while the remaining six students incorporated less than 50 percent. However in Cycle 2, the number of students who incorporated more peer feedback increased from four to seven students. This finding corroborated with the fact that students adopted feedback provided by their peers when revising their writing.

Table 2: Category for Incorporating Peer Feedback Category Percentage of feedback incorporated

\begin{tabular}{lr}
\hline Feedback on grammar from drafts and conferencing & 58 \\
Feedback on content from drafts and conferencing & 29 \\
Feedback from peer response form & 13
\end{tabular}


Based on the findings, a total of 1246 feedback were gathered from the students' multiple drafts which consisted of different categories of feedback. As shown in Table 2, writers incorporated 58 percent of feedback on structure and grammar from drafts and conferencing in their revisions, 29 percent on content from drafts and conferencing and 13 percent on content from the peer response form.

For errors on structure and grammar, all reviewers corrected the writers' errors by the direct method of underlining and providing the correct form, either at word, phrase or sentence level. This method proved to be more successful and more effective in revising errors. As a result, students did not have much problem in revising or making changes for feedback on error identification in both cycles. This was in line with a study conducted by Chandler (2003) which stated that direct correction and simple underlining were more effective in helping writers to produce accurate revision. The other reason for the focus on structure and grammar feedback was because of the over emphasis on writing accuracy. For students to get better marks in writing, they had to have minimal number of grammatical errors, thus their focus on grammatical accuracy at the expense of other aspects of writing.

On the other hand, students faced difficulty in incorporating both reviewers' feedback on content and also written peer feedback in the peer response form. Even if some of the feedback were incorporated by the writers, the revisions were unsuccessful as they did not match with what was actually the requirement of the feedback or sometimes the changes made were insignificant in improving the content of the essay. For example:

Draft 1:

Suddenly, there was a castle appeared from the lake. I made my way to the castle. In the castle, I could see there was a party. The prince came to me and asked me to dance with him.

At the side of this paragraph, the reviewer wrote her feedback:

Describe more on the castle, the party and how the prince looked like. It will make this part more interesting.

In Draft 2, after revising, the writer wrote:

Suddenly, there was a beautiful castle appeared from the lake. I made my way to the castle. In the castle, I could see there was a dancing party. The handsome prince came to me and asked me to dance with him.

From this example, it was noted that the feedback on content provided by the reviewer did not have much impact in making the paragraph more interesting. Only minimal changes were made by the addition of a single-word adjective to the subjects stated in the story. From the feedback, it was noted that the reviewer expected the writer to 'describe' at greater length the castle, party and the prince. By adding only an adjective would not bring much impact and difference to the writing.

Writers also found difficulty in understanding the peer feedback in the peer response form. This was because the comments were mostly too general and they feared that they might misinterpret the comments and produce more errors in their next draft. Written feedback on peer response sheet such as 'I don't like the ending' or 'Your beginning paragraph sounds boring', seemed difficult for the students to attempt any kind of change as they were too brief and general. However, the revision based on multiple drafts annotation was judged to be successful as writers incorporated most of the feedback provided by the peer reviewers. 


\section{Reduction in number of errors}

Based on the process of peer revision in both Cycle 1 and 2, the number of errors produced by student writers saw a drop from Draft 1 to Draft 3 . As shown in the table, verb tense was the most frequent error made by students. The numbers were reduced significantly from the first to the final draft (Draft 3). In Cycle 1, writers made a total of 87 tense errors in Draft 1 and the number dropped to 68 in Draft 2 and 43 in the final draft, showing a significant drop of 50.6 percent. In Cycle 2, a total of 71 tense errors were made and after peer revision, the number dropped to 46 and a further decrease to 34 ; accounting for a total of 52 percent reduction.

Besides verb tense, a significant reduction in number of errors was noted with other types of errors. For example in Cycle 1, for spelling, the percentage of error reduction from the first to the final draft was 73.4 percent, followed by preposition, 69.2 percent, word order, 69.1 percent, misused words, 68.6 percent, missing word 57.8 percent and subject-verb agreement 57.1 percent. The peer revision certainly had an impact in reducing number of errors based on the high percentage of reduction. In Cycle 2, students made the least number of errors on verb tense but subject-verb agreement recorded as the most frequent errors committed by the writers. Probably, after what had been learnt in Cycle 1, writers were more aware of the tenses when writing their essays but made careless mistakes with subject-verb agreement and word order. Even though subject-verb agreement was the highest in errors made in Cycle 2, it recorded a high percentage of 79.2 percent reduction. From 77 errors, as a result of peer revision, the number dropped to only 16 which indicated that the reviewers were able to provide correction due to their deep understanding of subject-verb agreement and which was effectively used by the writers in the next draft. Other than that, spelling was identified as an error that had recorded a drastic drop of 83 percent, and article by 75 percent. This was followed by verb tense with a 52 percent total reduction while for word order, from 73 errors in the first draft to 34 errors in the final draft. For this particular type of error, it was identified that only the female reviewers provided most of the correction. As for the male students who committed most of the errors, they did not receive the correction from their male reviewers. Misused word and missing word both showed a total of 34 percent reduction.

Figure 1: Data on Number of Errors made by Student Writers in between drafts in Cycle1

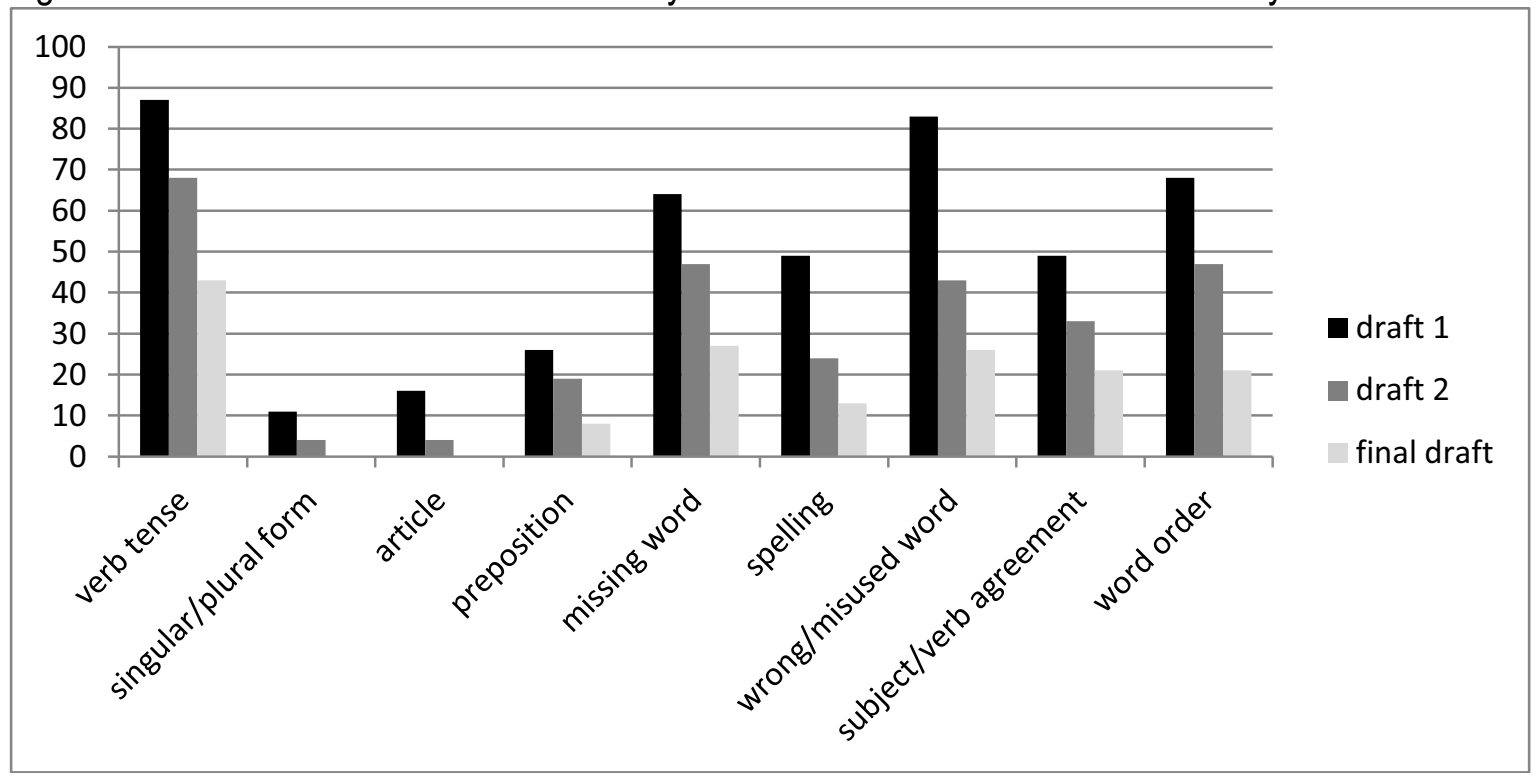


Figure 2: Data on Number of Errors made by Student Writers in between drafts in Cycle 2

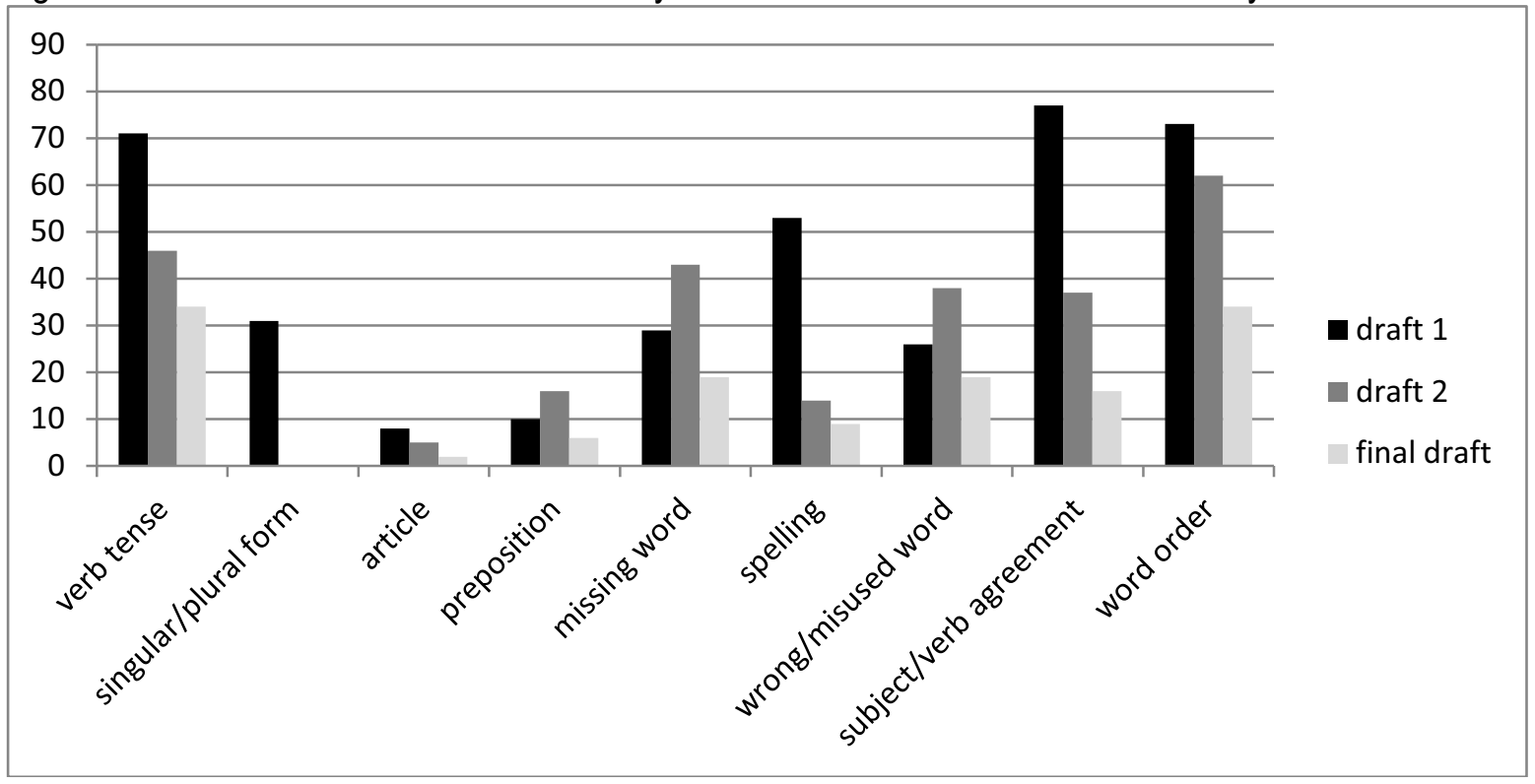

Although there was a distinct difference between the revision patterns in both cycles, the impact of peer revision in reducing number of errors was identified through subsequent revisions. The data from both graphs indicated that in Cycle 1, verb tense was the main focus of the revision and as a result, number of errors was reduced, not only in the final draft but also in Cycle 2. Several reasons for this were identified and it was found that, most reviewers were influenced by the main goal of obtaining accuracy in writing. To the students, accuracy means writing using the correct tenses. This also indicated that reviewers were able to facilitate students for revision because reviewers were able to underline and provide the correction. From the overall comparison, it was found that after experiencing the process of peer revision, writers were more aware of their own writing. Towards this end, students were able to produce improved final drafts with reduced errors.

However to see whether peer revision had an impact in reducing students' errors between cycles, a comparison was made between the total and percentage of errors made by students between Cycle 1 and 2. This is seen in Table 3.

Table 3: Total Number and Percentage of Annotated Errors in Cycle 1 and 2

\begin{tabular}{|c|c|c|c|c|c|}
\hline & \multirow[t]{2}{*}{ Type of Errors } & Cycle 1 & Cycle 2 & Cycle 1 & Cycle 2 \\
\hline & & \multicolumn{2}{|c|}{$\begin{array}{c}\text { Total number of } \\
\text { errors }\end{array}$} & \multicolumn{2}{|c|}{ Percentage (\%) } \\
\hline 1 & Verb Tense & 198 & 151 & 17.8 & 15.4 \\
\hline 2 & Singular/plural form & 15 & 8 & 1.4 & 0.8 \\
\hline 3 & Article & 20 & 17 & 1.8 & 1.7 \\
\hline 4 & Preposition & 53 & 51 & 4.8 & 5.2 \\
\hline 5 & Missing word & 138 & 115 & 12.4 & 11.7 \\
\hline 6 & Spelling & 86 & 49 & 7.7 & 5.0 \\
\hline 7 & Wrong/misused word & 152 & 134 & 13.7 & 13.6 \\
\hline 8 & $\begin{array}{l}\text { Subject/verb agreement } \\
\text { Word order }\end{array}$ & 103 & 109 & 9.3 & 11.1 \\
\hline \multirow[t]{2}{*}{9} & & 136 & 169 & 12.2 & 17.2 \\
\hline & Total & 901 & 805 & 52.81 & 47.18 \\
\hline
\end{tabular}


At a glance, it appeared that there was a reduction in terms of total number of errors made by student writers from Cycle 1 to Cycle 2. However, based on Table 3, the percentage of reduction of 5.6 percent seemed insignificant and it can be said that peer revision did not bring any significant impact in reducing number of errors in between tasks. This finding is displayed clearly in Figure 3 :

Figure 3: Data on percentages of errors made by student writers in Cycle 1 and Cycle 2

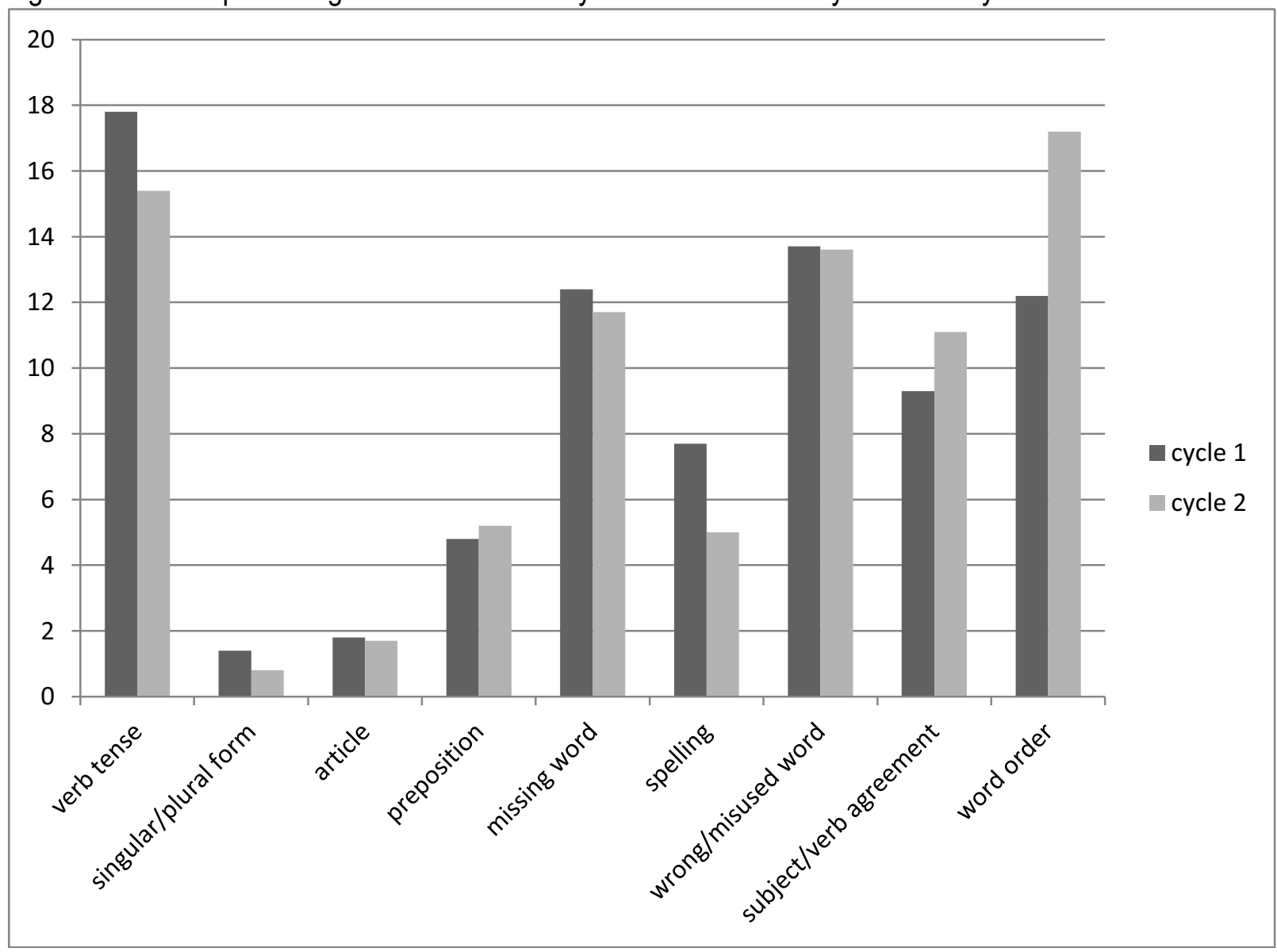

The pattern in Figure 3 suggests that there was not much difference in terms of the errors made by students between Cycle 1 and 2 . They made reduced errors of verb tense in Cycle 2 but made more errors of word order. While for others, the total reduction of errors compared from Cycle 1 to Cycle 2 was at a minimum. The possible factor was that writers did not receive sufficient input from the reviewers to improve their grammar knowledge. This explained why some errors were repeated and why reviewers even made use of the peer conferencing session to explain the errors. The explanations were done only at surface level as the reviewers themselves did not have in-depth or extensive knowledge on the subject matter in order to explain the rules.

Other than that, the main goal of writing was to produce a good final draft. This resulted in most writers being concerned only about correcting the errors than studying and understanding the errors for future writing. The corrections provided by peer reviewers seemed to affect the writers in terms of the level of initiative for self-correction. Writers were over dependent on the reviewers as they believed that the reviewers had pointed out all the errors and that there was no need for further revision and correction.

From the comparison in between drafts and between both cycles, peer revision was able to reduce number of errors and led to improvement in between drafts. As a result, students were able to 
write better essays. However, improvements could not be seen in terms of improvement in grammar knowledge as students still made a lot of errors in Cycle 2.

\section{Improvement in content and ideas}

Data from students' multiple drafts indicated improvement in students' writing in content and ideas. For content and ideas, changes were noted including use of apt and varied vocabulary. In addition sentence patterns were more varied which added more effect to the writing and for overall purpose of capturing the readers' attention. For improvement of content and ideas, two strategies were adopted by the reviewers. First, was additional input given to enable the writers to develop their points through explanation and illustration of the given point. This was considered a major text-based revision. Second, was where reviewers only made minimal revision by paraphrasing the text without affecting the meaning as had been intended.

Based on the drafts, it was found that most changes were meaning-preserving changes. This included paraphrasing the writers' sentences or changing the sentences or words within the text to more appropriate ones. The focus of this type of revision was on choice of vocabulary and repetition of words. For example:

Draft 1:

I could hear the burglar was inspecting the things in the living room. I quickly called the emergency number and picked up a hockey stick.

Draft 2:

I could hear the burglar was searching for valuable things in the living room. I immediately called the emergency number and quickly grabbed a hockey stick.

In the above example, the reviewer underlined the words (in italics), and suggested other words which he thought were more appropriate for expression of the intended meaning. The impact of the change, for example, from 'inspecting' to a more suitable and accurate word 'searching' seemed small, but using the right word enabled the writer to describe his intended meaning, as depicted in the following peer conferencing exchange.

Reviewer: For this part, why did you use the word 'inspecting'?

Writer : Oh, I nak cakap, pencuri tu macam cari-cari barang [Oh, I wanted to say that the burglar was like searching for something]

Reviewer: That's what I thought. You could use the word 'searching'. I think it's more suitable. Then, here, I add the word 'valuable' because he must be looking for expensive things like handphones, money or things like that.

Writer : Ooo..what about this? Apa beza 'quickly' and 'immediately' eh? [What's the difference between 'quickly' and 'immediately'?]

Reviewer: How eh to explain...? I think you should look up the dictionary.

From the discussion, we could infer that the reviewer was capable of providing suitable words based on his understanding of what the writer would probably have liked to express. To ensure that the words suggested were correct, the reviewer used the peer conferencing session to clarify what was the writer's intention. Negotiation of meaning took place but it can be concluded that the reviewer was unable to explain in detail on the difference in word choice. However, with regard to this aspect, the vocabulary was more precise and accurate thus improving the quality of the writing. 
Other than that, simple paraphrasing also helped improve the content and ideas in the writing although the effect was small, as in the following example:

Draft 1:

The village looked messed up from far. When I reached at the village, I saw a signboard. The signboard showed "Welcome to the Never End Journey Village". I felt something was wrong.

Draft 2:

The village was in such a mess. Upon reaching the village, the signboard grabbed my attention. It was written "Welcome to the Village of a Never Ending Journey". I could sense something was wrong.

From the excerpt of the first draft, the reviewer tried to paraphrase the text without affecting the original meaning and idea of the writer. Suggested sentences were provided by the reviewer in the next draft, which the writer was able to incorporate.

It was also discovered that, some reviewers attempted to transform the essay to fulfill their standard, even if it required them to make major changes at paragraph level. An example is shown below:

\section{Draft 1}

The voice of my mom became clearer and clearer. Suddenly I can see light through my eyes. I couldn't see anything and I saw the woman with white dress and she standing far away from me. She looked towards me and fly and laugh. She flying towards me and suddenly she dashed through me.

\section{Draft 2}

I could hear clearly my mom's voice as it was like a person nearing towards me. Then, a flash of light came out of nowhere flashing in my eyes. My vision went blurred and I saw a woman in white dress again and she was standing far away from me. She had long hair with long sharp nails. She looked at me and flew away while laughing sinisterly. She flew towards me and suddenly and she dashed through me. I felt like my soul had been ripped out of my body.

From the changes between the first and second draft, it can be seen that this reviewer had a better revision strategy as she had the ability to provide additional information that matched the writer's idea. The additional information provided not only more details but also length to the paragraph. Based on the discussion in the peer conferencing session, the reviewer highlighted the major issue with the writing. In solving this problem, when reviewing the paper together, the focus was more on discussing the writer's idea and adding more details to her story. As a result of the revision the writer was able to develop her ideas and with the help of the reviewer, it was found that the final story was more interesting and able to fulfill the required number of words.

\section{CONCLUSION}

The study has shown that peer revision does have a positive role in creating a rich learning environment in the context of an ESL learning classroom and nurturing the support needed by slower learners. For this, the peer reviewers have to be at a level higher than the writers in knowledge, language and skills for the transformation to occur. It was noted that reviewers were able to give constructive feedback in terms of ideas, complimenting where it is due, criticising constructively for clearer expression of ideas, suggesting alternative expressions where vague expressions were given and correcting wrong forms and incorrectly used expressions for accuracy. Although the study is limited to a small sample and hence the findings limited to the context in which it was conducted, it does give insights to understanding the contribution of peer revision as a tool to improve learners' writing. The 
study also highlights the fact that writers were more at ease with their peers to discuss difficulties with expressing certain feelings in the target language for lack of appropriate and varied vocabulary and pertinent expressions by resorting to translations and requesting for the relevant equivalents. While it can seen that the writers were improving with better vocabulary and expressions, so too did the reviewers in enhancing their knowledge, skills and language related to the topics for narration.

\section{REFERENCES}

Allaei, S.K. \& Connor, U. (1990). Exploring the dynamics of cross-cultural collaboration in writing classrooms. The Writing Instructor, 10, 19-28

Blasingame, J., \& Bushman, J. H. (2005). "Teaching writing in middle and secondary schools". Saddle River, N J: Pearson.

Chandle, J. (2003). The efficacy of various kinds of error feedback for improvement in the accuracy and fluency of L2 students' writing. Journal of Second Language Writing, p.276-296.

Carson, J.G. \& Nelson, G.L. (1996). Chinese students' perceptions of ESL peer response group interaction. Journal of Second Language Writing, 5, 1-19.

Chaudron, C. (1984). "The effects of feedback on students' composition revisions". RELC Journal 15(2), 1 -14.

Cho, K., Chung, T.R., King W.R. \& Schunn, C. (2008). "Peer-Based Computer Supported Knowledge Refinement: An Empirical Investigation". Communication of the ACM, 51(3), 83-88.

Donato, R.1(994). Collective scaffolding in second language learning' in J. P. Lantolf and G. Appel (eds.).Vygotskian Approaches to Second Language Research. Norwood, NJ: Ablex Publishing Corporation.

Elbow, Peter. Writing without Teachers. New York: Oxford, 1973. Faigley, Lester. "Nonacademic writing: The social perspective." In Writing in Nonacademic Settings, pp. 231-340. Less Odell and Dixie Goswami (Eds.) New York: Guilford Press, 1985.

Franklin, K. (2010). "Thank you for sharing: Developing Students' social skill to Improve Peer Writing Conferences". English Journal, 79-84.

Hansen, J.G. \& Liu, L. (2005). "Guiding Principles for Effective Peer Response". ELT Journal, 59, 31-38

$\mathrm{Hu}, \mathrm{G}$. (2005). Using peer review with Chinese ESL student writers. Language Teaching Research, 9(3), 321-342.

Keppell, M., Au, E. Ma, A. \& Chan, (2006) Peer learning and learning-oriented assessment in technology-enhanced environments. Assessment and Evaluation in Higher Education, Vol. 31, No. 4, August 2006, pp. 453-464

Knight, L.V. and Steinbach, T (2011) Adapting Peer Review to an Online Course: An Exploratory Case Study. Journal of Information Technology Education Volume 10, p.81-100.

Legge, Anne L. (1980). "Small groups in college writing classes: Why and how,".

Lu, R. And Bol, L. (2007). A comparison of anonymous versus identifiable e-peer review on college student writing performance and the extent of critical feedback. Journal of Interactive Online Learning, 6(2), p.100-115

Mendonça, C.O. \& Johnson, K.E. (1994). Peer review negotiations: Revision activities in ESL writing instruction. TESOL Quarterly, 28, 745-769.

Neubert, G.A. \& McNelis, S.J. (1990). Peer Response: Teaching Specific Revision Suggestions. English Journal, p.52-56.

Rollinsons, P. (2005)." Using Peer Feedback in the ESL Writing Class". ELT Journal, 59, 23-30

Stritjbos, JW, Narciss, S. and Dunnebier, K. (2010). Peer feedback content and sender's competence level in academic writing revision tasks: Are they critical for feedback perceptions and efficiency. Language and Instruction 20, p. 291-303.

Tsui, A.B.M \& Ng, M. (2000). "Do Secondary L2 Writers Benefit from Peer Comments?" Journal of second Language Writing, 9(2), 147-170 
Villamil, O.S. \& de Guerrero, M.C.M. (1996). Peer revision in the second language classroom: Socialcognitive activities, mediating strategies and aspects of social behaviour. Journal of Second Language Writing, 5, 51-75.

Vygotsky, L.S. (1978). Mind in Society: The Development of Higher Psychological Processes. Harvard University Press.

Wessa, P and De Rycker, A. (2010). Reviewing Peer Reviews - A Rule-based approach. Proceedings of 5th International Conference on e-learning, ICEL, Penang, p408-418.

Wood, D. and Kurel. F (2008). Engaging students in reflective practice through a process of formative peer review and peer assessment. ATN Assessment 08: Engaging Students with Assessment. 